\title{
GHR - \\ GeOrges Henri Riviere OG FOLKEMUSEETS GENESIS I FRANKRIKE
}

Marc Maure

Georges Henri Rivière (1897-1985), oftest bare kalt GHR, er en av de store skikkelsene $i$ moderne museologi. Få har spilt en så omfattende rolle og hatt så stor innflytelse på utviklingen av museumsvesenet $i$ vårt tid, både i sitt hjemland og $i$ verden forøvrig. GHR stod ikke bare bak opprettelsen av mange museer, men skapte også helt nye museumsmodeller. Han var både - og med stor talent - museolog og museograf, pedagog, scenograf og inspirator for flere generasjoner av museumsfolk. Faglig bredde, kombinasjon av teoretisk innsikt og organisasjonstalent, grundighet, kreativitet og åpenhet for nye ideer, var viktige kjennetegn ved hans mangeårige virksombet. I utlandet er GHR sarlig kjent for en utrettelig innsats for museumssaken i internasjonal sammenheng, i egenskap av ICOMs (International Council of Museums) forste direktør fra 1947 til 1964 og permanente rådgiver fra 1968 til 1985.

I denne artikkelen har vi valgt å presentere GHRs rolle for utviklingen av museene for folkekultur i Frankrike, ved å legge vekt på situasjonen i 30 åra, som på mange måter er å betrakte som en nøkkelperiode i denne sammenhengen. GHRs arbeid strekker seg over en periode på ca. 50 år og ble svært betydningsfull. Isac Chiva, fransk etnologiprofessor, karakteriserer GHRs rolle slik: "Rarely can the expansion of a field of knowledge, both scientific and aesthetic, be illustrated by the life of a single man. Rarer still is it to see this influence become part of institutions and sensivities. [...] To GHR we largely owe the awakening of the present ethnografic view of France and especially as it is reflected in contemporary museography." (Chiva 1986: 539).

\section{DEN GLEMTE FOLKEKULTUR}

I 1936, når GHR publiserte artikkelen "Les musées de folklore à l'étranger et le futur Musée français des arts et traditions populaires" ("Klassikeren" presentert foran 
122 s. $117-120$ i dette nr. av Nordisk Museologi), lå Frankrike langt etter i forhold til de aller fleste europeiske land, når det gjaldt den plass folkekulturen hadde både i forsknings- og museumssammenheng.

Før opprettelsen av Institut d'Ethnologie ved Paris Universitet i 1925, var den franske "ethnologie"1 uten akademisk basis. I slutten av 1920-årene og utover i 30-årene, ble faget etterhvert bygget opp som autonom og moderne kulturvitenskap, institusjonalisert og profesjonalisert. Det skjedde ved løsrivelse fra fysisk antropologi og fusjon av uensartede tradisjoner, som blant annet den eldre folkloristikk. Miljøet rundt Musée d'Ethnographie du Trocadéro spilte den sentrale rollen i denne prosessen (Chiva 1986, Jamin 1989).

I midten av 1930-årene bestod det franske museumsvesenet hovedsakelig av kunstmuseer og arkeologiske museer. Frankrike var uten et nasjonalt folkemuseum. Utenfor Paris eksisterte det bare et tyvetalls lokale og regionale museer med samlinger om folkekultur. Av disse var de rene folkemuseene få. Det fantes i Frankrike ikke friluftsmuseer.

Kontrasten med situasjonen i de nordiske land var stor. Spesielt stor var kontrasten med den norske situasjonen, kjennetegnet ved bondekulturens dominerende status som nasjonal kulturarv. I Frankrike, - eldre nasjon bygd opp gjennom flere hundre år og sentralisert omkring Paris, kongesete og senere republikkens hovedstad -, var derimot bondekulturen stigmatisert. Den var uttrykk for "regionalisme", - dvs kulturelt etterslep, konservatisme og separatisme -, og en trussel for det nasjonale fellesskap.

Historien til utviklingen av museer for folkekultur i Frankrike i løpet av vårt århundre fram til våre dager, er derfor historien om kampen om folkekulturens nasjonale verdi og status, og om legitimiteten av studie, vern og formidling av folkekultur. GHR har vært en av de fremste forkjemperne for denne saken. Han har oppnådd mange betydningsfulle resultater, med tidvis store vanskeligheter, og ikke uten nederlag.

\section{DE FØRSTE MUSEENE FOR FOLKEKULTUR}

Musée d'Ethnographie du Trocadéro ble opprettet i 1878 i kjølevannet av verdensutstillingen som var arrangert i Paris samme år, og lokalisert i Palais du Trocadéro, et bygg reist $\mathrm{i}$ forbindelsen med denne utstillingen. Det var et museum for generell etnografi, dvs med hovedvekt på ikkeeuropeiske etnografika, samt en liten samling av fransk folkekultur (Jamin 1989). Ideen om å opprette et slikt museum var ikke ny, men her som i mange andre sammenhenger, ble en verdensutstilling den utløsende faktor. Presentasjon av bygninger og drakter fra bondekulturen fra forskjellige land hadde tradisjonelt hatt en stor plass i tidligere verdensutstillinger. Slike presentasjoner hadde møtt stor publikumssuksess under utstillingene i Paris i 1867 og 1878, og på forskjellige måter aktualisert behovet for en permanent presentasjon av den franske bondekulturen. ${ }^{2}$

I 1884 ble "Salle de France" ved Musée d'Ethnographie du Trocadéro åpnet for publikum. Museet presenterte der for første gang, på et beskjedent areal på $130 \mathrm{~m}^{2}$, sin franske samling. Denne samlingen bestod av en kjerne av gjenstander og utstillingsdukker ervervet fra verdensut- 
GHR sammen med Joséphine Baker (han badde noen air tidligere skrevet en melodi for benne) $i$ utstillingen laget i Musée d'Ethnographie du Trocadéro $i$ 1933, med gjenstander samlet under det store feltarbeid "Mission DakarDjibouti".

GHRs omfattende kontakter med Paris' kunstverden kom ofte til nytte når det gjaldt å organisere, finansiere og skape interesse for museets virksomhet (foto MNATP).

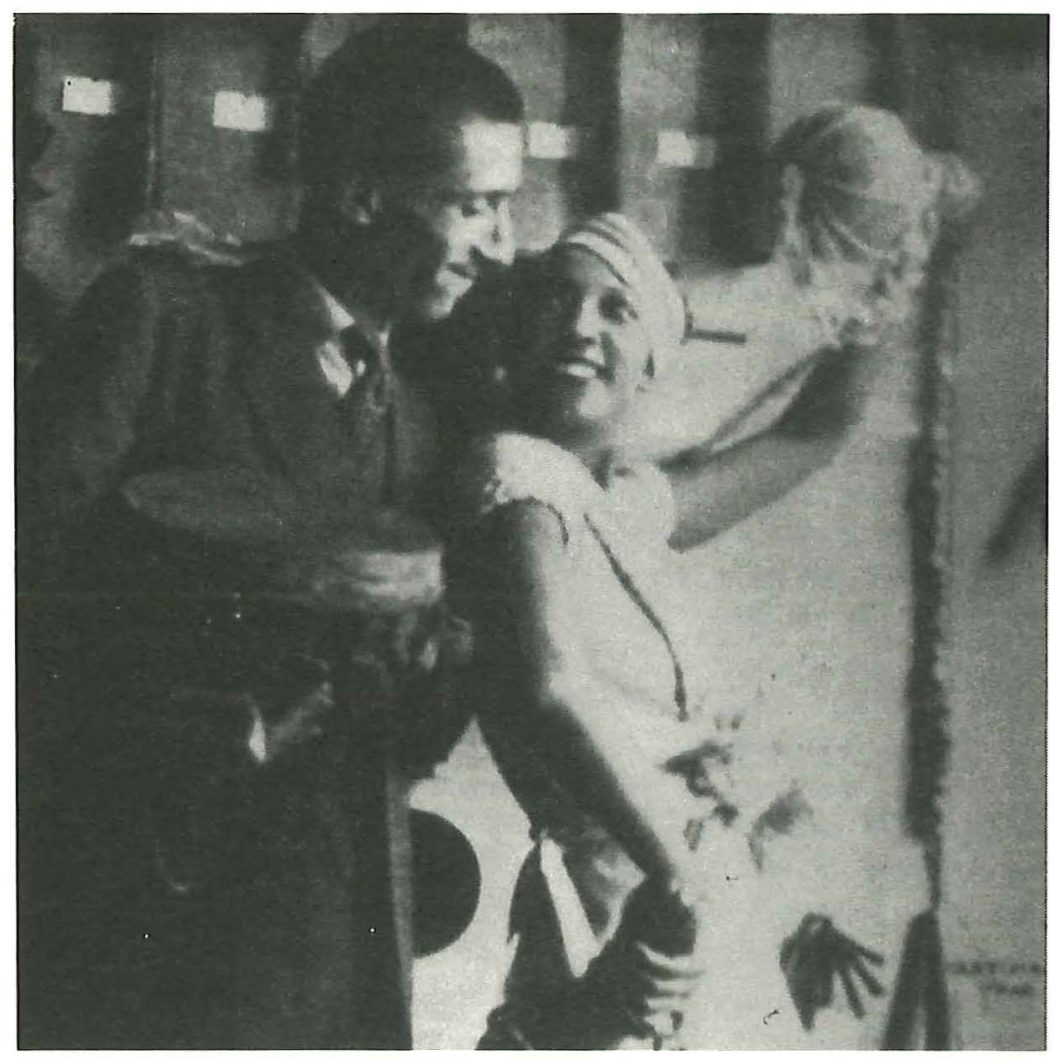

stillingen i 1878, og som etterhvert hadde blitt utvidet ved innkjøp og gaver (Noël 1987).

Parallelt med og uavhengig av det som skjedde i Paris, hadde det i provinsen blitt opprettet enkelte samlinger med gjenstander fra bondekulturen. Men i forhold til det som samtidig skjedde i andre europeiske land, var prosessen ganske beskjeden, og tok først og fremst form av samlinger innenfor rammen av byhistoriske museer (Collet 1987). Noen få regionale folkemuseer hadde sett dagens lys. De første - og stort sett de eneste ved århundreskiftet var Musée Breton i Quimper (1874), Museon Arlaten i Arles (1896) og Musée
Alsacien i Strasbourg (1902). Det er verdt å merke seg at disse museene befant seg i områder som språklig sett og kulturelt representerte de minst franske områder av Frankrike. Det gjelder henholdsvis Bretagne, Syd-Frankrike (Oksitania) og Alsace, områder innlemmet i den franske stat i ulike perioder, og preget av sterke regionalistiske bevegelser i slutten av forrige århundre. Der fant man spesifikke kulturelle kontekster, hvor bondekulturen ble brukt som hovedelement for skaping, vedlikehold og markering av en etnisk identitet. 
PAUL RIVET OG GEORGES HENRI RIVIERE

I 1928 ble Paul Rivet, professor ved Museum d'Histoire Naturelle i Paris (det nasjonale naturhistoriske museum), utnevnt som direktør for Musée d'Ethnographie du Trocadéro. Museet hadde siden opprettelsen, vært offer for myndighetenes manglende interesse, med påfølgende fravær av ressurser og faglig politikk. Museet var i dårlig forfatning: "Innstallert $\mathrm{i}$ et bygg reist for et helt annet formål, mørkt og ikke oppvarmet, innredet med improviserte glassmontre - dårlig beskyttet mot støv, fuktighet og insekter -, uten dokumentasjonsavdeling, uten arbeidsrom, uten magasin og uten katalog, - så museet nærmest ut som en marsjandisebutikk". ${ }^{3}$ Museet ble stengt for å bli omorganisert og ombygd. Rivets hovedmål var å gjøre det til en moderne forsknings- og formidlingsinstitusjon. En av hans intensjoner var også å løsrive den franske avdeling som egen institusjon.

Rivet hadde allerede spilt en viktig rolle for etableringen av etnologi som egen vitenskapelig disiplin. Under hans ledelse ble museet utviklet til å være Frankrikes største fagmiljø på dette feltet. Rivet var medlem i det sosialistiske parti, og ble en av Front Populaire's ${ }^{4}$ første folkevalgte. Han var dessuten aktiv i forskjellige organisasjoner mot fascismen og rasismen (Jamin 1989). Dette er viktig for å forstå den sterke folkeopplysningsideologien som preget omorganiseringsarbeidet .

I 1928 tok Rivet kontakt med GHR, som hadde gjort seg bemerket som arrangør av en stor og suksessrik utstilling om det førkolombianske Amerika. Han tilbød ham stillingen som underdirektør, for å arbeide med det store prosjektet.

GHR gjorde på denne måten sin entre på museumsscenen, uten å kunne vise til noen formell kompetanse hva angikk museumsarbeid i vanlig forstand. Han var musiker og pianist av utdanning og yrke. Som sådan var han meget eklektisk, med bredt interessefelt, fra samtidens avantgarde-musikk til music-hall og jazz. Uformell utdannelse om kunsthistorie og gjenstandskultur hadde han fått gjennom nær kontakt med sin onkel Georges Rivière, som var kunstner, samler og forfatter av kunstbøker. Gjennom 1920-årene hadde GHR vært - både som musiker, skribent, og arrangør av forskjellige kulturelle og sosiale begivenheter - en aktiv deltaker i Paris myldrende kultur- og sosietetsliv, og omgikk alle som betydde noe i denne sammenhengen. Det gjaldt så vel den kunstneriske avantgarde - og de sentrale skikkelsene innenfor billedkunst, musikk og litteratur ${ }^{5}$-, som innflytelsesrike og pengesterke personer som bankmenn, kunstsamlere og politikere. Denne allsidige virksomheten var kjennetegnet ved en stor åpenhet og interesse for alt som var nyskapende, og samtidig en utpreget talent som organisator (Leroux-Dhuys 1989). ${ }^{6}$

\section{MOT MUSÉE DE L'HOMME OG MUSEEE NATIONAL DES ARTS ET TRADITIONS POPULAIRES}

Fra 1929 begynte GHR å arbeide sammen med Paul Rivet, og i nær kontakt med noen av de daværende fremste etnologer og antropologer (som bl.a. Marcel Mauss og Arnold van Gennep), med omdanningen av Musée d'Ethnographie du Trocadéro til et moderne museum. Målsettingen var 
omfattende. Det gjaldt å bygge opp en ny institusjon, og helst to: Musée de l'Homme og Musée Français (som GHR ønsket å kalle det). I begge tilfeller dreide det seg om samme konsept, dvs en institusjon som bygger på et nært samspill mellom forskning og popularisering, og med begge virksomheter like høyt prioritert. For det første skulle museet være et "musée-laboratoire", dvs ikke bare en samling, men et dokumentasjons- og studiesenter fungerende som redskap for forskningen. Det innebar bl.a. et nytt syn på gjenstandens betydning som kilde - en forlater den tradisjonelle vektlegging på det estetiske og det kuriøse -, en målrettet og systematisk innsamlingspolitikk, og oppbygging av arkiv, bibliotek, katalog, etc (Jamin 1985). For det andre skulle museet være et redskap i folkeopplysningens tjeneste. "Dette museet skal være det første i Frankrike som i virkeligheten blir tilgjengelig for alle, fordi det skal være åpent om kvelden, dvs når de som arbeider er frigjorte fra deres profesjonelle forpliktelser og har rett til å bruke deres fritid til opplysningsaktiviteter [...] Museet skal gjøre alt som står i sin makt for at vår vitenskap, som på mange måter er atskillig kompleks, blir tiltrekkende og forståelig for alle". ${ }^{7}$

Museet stod for en omfattende virksomhet i begynnelsen av 30-årene. Det organiserte og gjennomførte omfattende tverrfaglige feltarbeid og innsamlingskampanjer i Afrika og Latin Amerika. Store utstillinger ble arrangert med det innsamlede materiale.

GHR spilte en nøkkel-rolle for organiseringen og finansieringen av denne virksomheten, samtidig som han arbeidet med prosjektet for opprettelsen av det franske folkemuseet. Han foretok studiereiser i 125 utlandet allerede i 1929, hvor han bl.a. besøkte Skansen. Han lagde planer og søkte etter lokaliseringsmuligheter. Diverse ideer ble utredet, men uten resultat. Et konkret prosjekt om etablering av museet $\mathrm{i}$ et bygg reist i tilknytning til Exposition Coloniale Internationale i Paris i 1931, med friluftsmuseum i Vincennes-skogen, ble ikke gjennomført (Jamin 1989).

I 1935 ble det gamle Palais du Trocadéro revet ned, for å gi plass til Palais de Chaillot, som del av infrastrukturen for verdensutstillingen som skulle holdes i Paris i 1937. Etter utstillingen flyttet det nye Musée de l'Homme inn i bygget.

\section{MUSÉE NATIONAL DES ARTS ET TRADITIONS POPULAIRES (MNATP)}

MNATP ble opprettet som egen institusjon med GHR som direktør den 1. mai 1937 (merk datoens symbolske betydning), og installerte seg i Palais de Chaillot med Musée de l'Homme som nabo. Museets opprettelse var resultat av politisk vilje fra Folkefrontens sosialistiske regjering. En kan i ettertid spørre seg både om når og hvorvidt museet $\mathrm{i}$ det hele tatt hadde vært opprettet, hvis Folkefronten ikke hadde kommet til makten.

Museets situasjon før krigen var langt fra tilfredsstillende. Det kom til å gå mer enn 30 år før det museet GHR drømmer om, så dagens lys. Begrensede arealer gjorde det ikke mulig å lage permanente utstillinger. Museet møtte dessuten store finansieringsproblemer helt fra begynnelsen. Til tross for vanskeligheter og begrensninger, åpnet museet et dokumentasjonssenter for forskere, og begynte å foreta noe feltarbeid (Noël 1989). 
Marc Maure

126 Under krigen ble MNATP stengt, men gikk samtidig gjennom en meget aktiv og viktig periode. Museet som kunne takke en sosialistisk regjering for opprettelsen, kom til å skylde den tyskvennlige Vichyregjering sin faglige utvikling. Arsaken til det var at den tradisjonelle bondekulturen ble oppvurdert i den nye politiske konteksten. Bonden og hans kultur var nå hovedsymboler for den franske nasjonens autentisitet og kontinuitet (Faure 1989). Museet dro stor økonomisk nytte av kulturprogrammet for nasjonal gjenreisning igangsatt av regjeringen, og gjennomførte omfattende innsamlings- og dokumentasjonskampanjer i forskjellige områder i Frankrike. De tverrfaglige metodene utviklet under 30 årene ble da tatt i bruk, med den franske rurale verden som studieobjekt.

Etter krigen stod museet for en omfattende virksomhet $\mathrm{i}$ form av skiftende utstillinger i Palais de Chaillot, forskjellige aktiviteter i regionene, oppbygging av samlinger og arkiv, m.m. Samtidig ble museets framtidige virksomhet og anlegg planlagt. Museets nye bygg, i nærheten av Bois de Boulogne, ble reist og etterhvert tatt i bruk i løpet av 60-årene.

Det nye MNATP var i sin form og sin struktur, resultat av mange års refleksjon, eksperimentering og erfaring. Det var et "musée-laboratoire", bygd på en sammenkobling mellom selve museet og et etnologisk forskningsinstitutt, Centre d'Ethnologie Française. Museets permanente utstillinger bestod av to hoveddeler, i pakt med modellen beskrevet i GHRs artikkel fra 1936. Museet ble åpnet for publikum i 1972, med "galerie d'étude", en systematisk og typologisk presentasjon av gjenstander, ledsaget av informative elementer.
I 1976 ble "galerie culturelle" åpnet med en tematisk og syntetisk presentasjon av den franske folkekulturen utarbeidet sammen med Claude Lévi-Strauss (Desvallées 1989).

Gjennomføringen av prosjektet bød på mange problemer av økonomisk og administrativ karakter, som hindret den fulle utviklingen av GHRs program. Dessuten, på grunn av en konflikt med daværende kulturminister André Malraux, ble GHR pensjonert i 1967 og ikke i stand til å følge opp prosjektet helt til slutten.

\section{DE REGIONALE MUSEENE}

Parallelt med sitt arbeid for MNATP var GHR engasjert i utviklingen av museer for folkekultur rundt omkring i Frankrike. Det første trinn i prosessen ble, fra slutten av 50-årene, opprettelsen av det han kalte "musées régionaux de synthèse". Ideen var å opprette et museum $\mathrm{i}$ hver regional hovedstad, som skulle danne en syntese av regionens kulturhistorie. De skulle integrere det historiske, det etnologiske og det arkeologiske perspektivet. De skulle være senter for et nettverk av lokale museer i hele deres region. Disse regionale museene, slik GHR tenkte seg dem, representerte en ny museumsmodell. Dette skyldes deres tverrfaglighet, hvor samtidsdimensjonen og deres desentraliserte struktur var viet en stor betydning.

Programmet ble ikke gjennomført i sin helhet. Flere regionale museer ble opprettet i løpet av 1960 og -70 åra, men med ujevne resultater. Det eldste og mest fullførte av disse museene er Musée de Bretagne i Rennes (1960). Ellers kan nevnes Musée de Normandie i Cæn, Musée d'Aquitaine i Bordeaux, Musée Daup- 


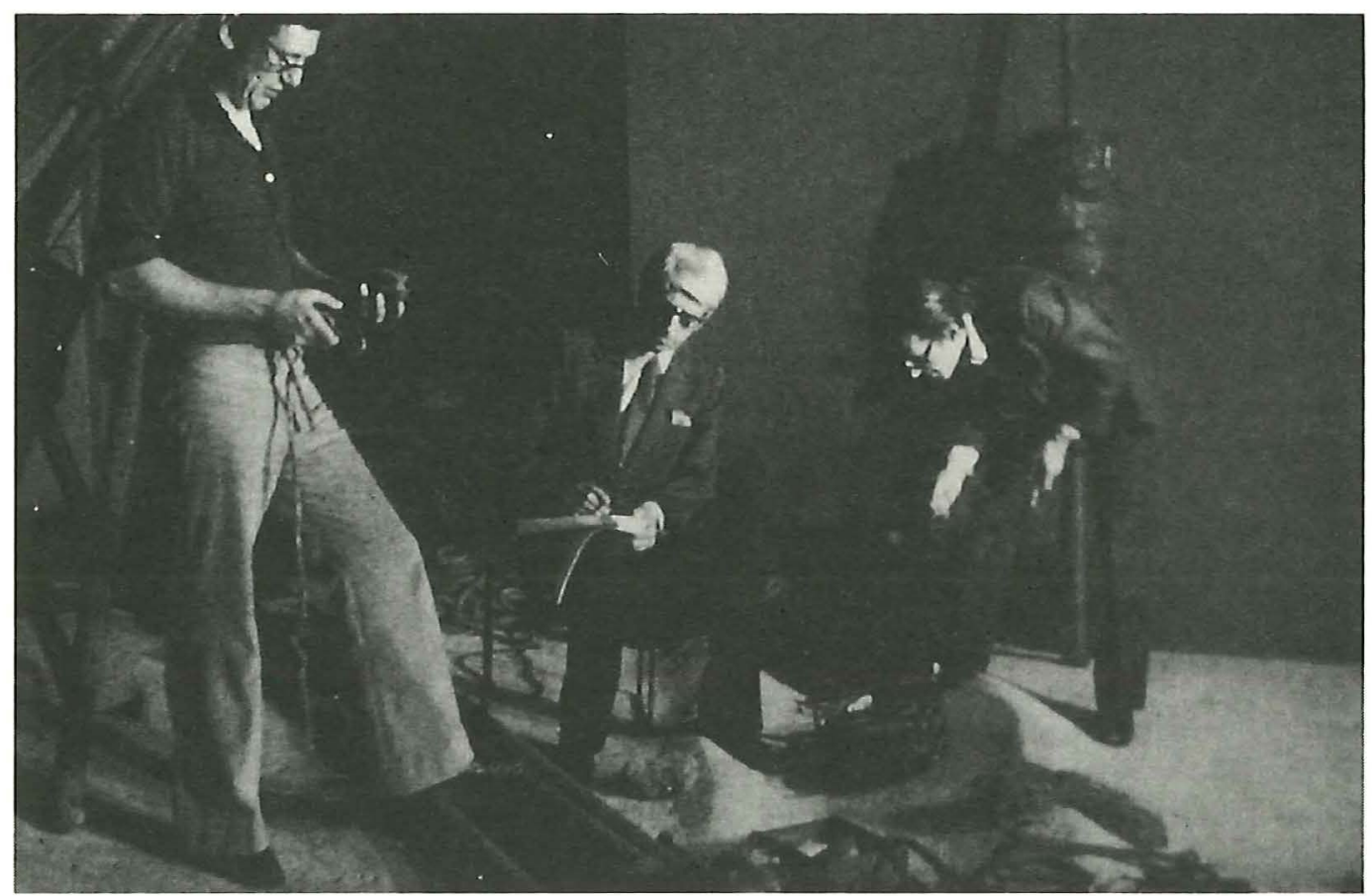

GHR (sittende) under arbeid med produksjon av utstillingene i "galerie culturelle" $i$ Musée National des Arts et Traditions Populaires $i$ 1974. GHR stod for utvikling av en saregen utstillingsfilosofi-og stil, som bygger på en kombinasjon av en funksjonalistisk inspirert estetikk og sterke krav til utstillingens faglige innhold. De permanente utstillingene ved MNATP er det beste eksemplet på denne stilen, som en ogsa finner i flere andre museer $i$ Frankrike og $i$ utlandet (foto MNATP).

hinois i Grenoble (Hubert 1993, Veillard 1989).

\section{ØKOMUSEENE}

Allerede i 1936 planla GHR å opprette lokale museer med friluftsavdelinger i hele Frankrike. Men prosjektet ble ikke konkretisert før 30 år senere, og da under en helt annen form enn det tradisjonelle friluftsmuseet. I 60-årene var GHRs målsetting å opprette det han kalte "musées du temps et de l'espace". Det skulle være lokale museer bestående av to hovedelementer: et museumssenter under tak ("musée du temps") med en syntese av områdets natur- og kulturhistorie, og en infrastruktur i landskapet ("musée de l'espace") bestående av kulturminner in situ, stier, informasjonssentra, m.m.

Det nyskapende ved modellen lå i anvendelsen av et integrerende økologisk perspektiv, som vektla samspillet mellom mennesket og naturgrunnlaget. Nyskapende var også rollen museet var tiltenkt som redskap for samfunnsutvikling, med aktiv medvirkning av lokalsamfunnets medlemmer. ${ }^{8}$

Det ble opprettelsen av de regionale naturparkene (Parcs Naturels Regionaux) i 
1281967 som utgjorde den utløsende faktoren. I løpet 1970-årene ble flere parker opprettet, og under GHRs påvirkning og takket være en positiv kombinasjon av ideologiske, politiske og økonomiske faktorer -, ble "økomuseene" - som de ble kalt fra 1971 - en naturlig del av deres infrastruktur. Økomuseumsbegrepet fikk dessuten, utover i 1970 og -80 årene, en omfattende internasjonal anvendelse (Gjestrum \& Maure 1988, Maure 1992).

\section{FRAMTIDEN TIL}

\section{MUSEENE FOR FOLKEKULTUR}

I dag er den gamle striden om folkemuseenes betydning og eksistensberettigelse fortsatt levende. Musée National des Arts et Traditions Populaires er gjenstand for debatt og omorganisering. Planer om å nedlegge det har vært drøftet tidlig i 1990-årene. En kan ikke nekte for at museet publikumsmessig har fungert dårlig og bare kan vise til lave besøkstall. Dette kan virke paradoksalt, ettersom få museer noen gang har blitt så grundig planlagt over lang tid som dette. Denne situasjonen skyldes sannsynligvis flere ulike faktorer. Det har blitt hevdet at hovedårsaken kunne ligge i selve GHRs konsept. Samtidig er det et faktum at hans planer ikke er blitt gjennomført i sin helhet, og at hans intensjoner ikke alltid er blitt respektert av hans etterfølgere. Det har også vist seg at "musée-laboratoire"modellen, kjennetegnet ved harmonisk samspill mellom forskning og formidling, i praksis hadde utviklet seg til en noe ensidig vektlegging på forskningsoppgavene. En kan dessuten spørre seg om noen av årsakene til Paris-befolkningens manglende interesse også kan være at den tradisjo- nelle bondekulturen egentlig har mistet mye av sin mening, for en befolkning urbanisert gjennom flere generasjoner.

Utenfor Paris har det franske museumslandskapet vært gjenstand for omfattende endringer i løpet av 1970- og 80-årene. En stor aktivitet på det lokale nivå, hvor kommuner og lokale organisasjoner har spilt en sentral rolle, har ført til opprettelse av en mengde museer og samlinger. Dette har ofte skjedd uten overordnet politikk eller faglig styring. Dette har skapt en uoversiktlig og konfliktfull situasjon, som er ytterligere forsterket av to hovedelementer: en administrativ struktur $o g$ et finansieringssystem som prioriterer kunstmuseene, og et stadig mer vanntett skille mellom forskningssystemet og museumssystemet (Chiva 1993). Fremtiden til museene for folkekultur i det nåværende museumssystemet har, $\mathrm{i}$ løpet av de siste årene, vært tema for omfattende debatt i det franske museumsmiljøet. Deltakerne på en stor konferanse arrangert i Mulhouse i 1991 uttalte i en felleserklæring at: "deltakerne er overbeviste om at den fulle utviklingen av disse museene ikke er mulig innenfor det nåværende administrative system" (Barroso 1993: 213).

\section{RÉSUMÉ}

Georges Henri Rivière est une grande figure de la muséologie moderne. Son influence sur le développement des musées, en France aussi bien qu'à l'étranger, a été importante. L'article met l'accent sur le rôle essentiel joué par GHR dans le développement des musées d'ethnographie française, et tout particulièrement sur la situation durant les années 30. A cette époque, à la différence entre autres des pays nordiques, la France est marquée par un pro- 
fond retard, concernant la place accordée à la culture populaire, dans le système de la recherche comme dans celui des musées. Les raisons de ce retard doivent être cherchées dans la signification accordée à la culture paysanne dans le contexte historique français. Elle n'a pas de statut comme patrimoine national, mais est au contraire stigmatisée et son existence représente un danger pour l'homogénéité de la nation. L'histoire du développement des musées d'ethnographie en France peut être considérée comme l'histoire d'un combat ayant pour objet le statut national de la culture populaire, et la légitimité de son étude, de sa préservation et de sa diffusion. GHR est l'un des grands champions de cette cause. Son action s'étend sur plus de 50 ans, et concerne la création du Musée National des Arts et Traditions Populaires à Paris, aussi bien que le développement des musées d'ethnographie en province, comme les musées régionaux de synthèse et les écomusées.

\section{NOTER}

1. I Frankrike har faget "ethnologie" både den hjemlige folkekultur og primitive fremmedkulturer som studieobjekt - dvs integrerer etnologi og sosialantropologi - . "Ethnographie" utgjør fagets deskriptive del.

2. Blant annet hadde Södermans figurer i den svensk-norske avdelingen i 1867 og Hazelius' tablåer fra Skandinavisk-etnografiska samlingen i 1878 skapt stor oppmerksomhet. En fransk journalist skrev etter å ha sett Hazelius' dioramaer (Collet 1987: 75): "Denne utstillingen som begeistrer barnepikene og bøndene, som derimot står uberørt overfor vidunderne utstilt i de andre paviljongene, bør ikke desto mindre tiltrekke de opplyste besøkendes oppmerksomhet. [...] Det er åpenbart at det ville være av stor verdi å ha et museum av denne typen. [...] Hvis en ønsker å lage Frankrikes etnografiske museum er det allerede nesten for sent; i noen få år vil det bare være en arkeologisk foretagende" (E. Villetard,

"Promenades à travers l'Exposition universelle", Le Correspondant, 10.10.1878).

3. Rivet, Paul \& Rivière, Georges Henri. 1931. "La réorganisation du Musée d'Ethnographie du Trocadéro", Bulletion du MET, 1:3, Paris, Norsk oversettelse ved Marc Maure.

4. Folkefront bygd på allianse mellom de venstreradikale partiene og fagbevegelsen, som dannet regjering etter valgseier i 1936, og stod for omfattende sosiale reformer $i$ årene før krigen.

5. GHR hadde bl.a. nær kontakt med kunstnere fra den surrealistiske bevegelsen, hvor interessen for primitive kulturer var spesielt stor. Se, når det gjelder forholdet mellom surrealister og antropologer i Paris på den tid, Jamin, Jean. 1986.

"L'ethnographie mode d'inemploi; de quelques rapports de l'ethnologie avec le malaise de la civilisation", in Hainard, Jacques (ed), Le mal et la douleur, Neuchâtel (Musée d'Ethnographie de Neuchâtel)

6. Det finnes mange eksempler på hvordan GHR brukte sine sosiale kontakter for å få organisert og finansiert forskjellige kulturarrangementer. Den første fremførelsen av Georges Gershwins Rapsody in Blue i Paris, er et særlig kjent eksempel på det.

7. Rivet, Paul. 1936. "Ce que sera le Musée de l'Homme", L'ouvre, 14. juni, Paris.

8 "An ecomuseum is an instrument conceived, fashioned and operated jointly by a public (eg local) autority, and its local population. [...] It is a mirror on which the local population views itself to discover its own image, in which it seeks an explanation of the territory to which it is attached and of the populations that have preceded it. [...] It is a mirror that the local population holds up to visitors [...] It is an expression of man and nature. It situates man in his natural environment. It portrays nature in its wildness, but also as adaptet by traditional and industrial society in their own image. It is an expression of 
130 time, when the explanations it offers reach back before the appearance of man, ascend the course of the prehistoric and historical times in which he lived and arrive finally at man's present. It also offers vistas of the future, while having no pretentions to decision-making, its function being rather to inform and critically analyse.[...]" (Rivière 1985)

\section{LITTERATUR}

Barroso, Eliane \& Vaillant, Emilia (ed). 1993. Musées et sociétés. Paris (Actes du colloque national musées et sociétés, Mulhouse, juin 1991; Direction des musées de France)

Bloch, Marc. 1993. "Om friluftsmuseer och bygdemuseer i Skandinavien 1930", Nordisk Museologi, no 1 , Umeå

Chiva, Isac. 1986. "Georges Henri Rivière: fifty years in the ethnology of France", Social Science Information, vol 25, no 3. London (International Social Science Council)

Chiva, Isac. 1993. "L'ethnologie de la France et les musées", in Barroso, Eliane \& Vaillant, Emilia (ed). 1993. Musées et sociétés. Paris

Collet, Isabelle. 1987. "Les premiers musées d'ethnographie régionale en France", in Cuisenier, Jean (ed), Muséologie et ethnologie. Paris

Desvallées, André. 1989. "Les galeries du Musée national des Arts et traditions populaires", in Weis, Hélène (ed). La muséologie selon Georges Henri Rivière. Paris

Desvallées, André. 1992. "Museology and cultural identity", Papers in Museology, 1, Umeå (Acta Universitatis Umensis)

Faure, Cristian, 1989. Le projet culturel de Vichyfolklore et révolution nationale 1940-1944. Lyon

Gjestrum, John Aage \& Maure, Marc (ed). 1988. $\varnothing$ komuseumsboka - identitet, okologi, deltakelse. Tromsø (Norsk ICOM)

Hubert, François. 1993. "Les musées de synthèse", in Barroso, Eliane \& Vaillant, Emilia (ed). 1993.
Musées et sociétés. Paris

Jamin, Jean. 1985. "Les objets ethnographiques sont-ils des choses perdues?", in Hainard, Jacques (ed), Temps perdu, temps retrouvé. Neuchâtel (Musée d'Ethnographie de Neuchâtel)

Jamin, Jean. 1989. "Le musée d'ethnographie en 1930: l'ethnologie comme science et politique", in Weis, Hélène (ed). La muséologie selon Georges Henri Rivière. Paris

Leroux-Dhuys, François. 1989. "Georges Henri Rivière, un homme dans le siècle", in Weis, Hélène (ed). La muséologie selon Georges Henri Rivière. Paris

Maure, Marc. 1992. “Økomuseum - om et nytt begrep", in Rapport fra Nordisk

Økomuseumseminar. Samsø (Økomuseum Samsø)

Noël, Marie-France. 1987. "Du musée d'Ethnographie du Trocadéro au musée National des Arts et traditions populaires", in Cuisenier, Jean (ed), Muséologie et ethnologie. Paris

Rivière, Georges Henri, 1985. "The ecomuseum an evolutive definition", Museum, 148, 1985

de Varine, Hugues. 1989. "Le rôle international de Georges Henri Rivière", in Weis, Hélène (ed). $L a$ muséologie selon Georges Henri Rivière. Paris

Veillard, Jean-Yves. 1989. "Georges Henri Rivière et les musées d'histoire: l'expérience de Rennes", in Weis, Hélène (ed). La muséologie selon Georges Henri Rivière. Paris

\section{TEKSTER FRA GHR}

GHRs virksomhet som faglig forfatter var begrenset. Det følgende er listen over GHRs artikler av museologisk karakter publisert siden 1960. GHRs tekster publisert i tidsskriftet Museum finnes også i engelsk versjon.

"Le musée de Bretagne, Rennes", Museum ,14 (4), 1961

"Musées et autres collections publiques d'ethnologie" in Poirier J. (ed) Ethnologie générale. Paris, 1968 
"Le musée de plein-air des landes de Gascogne",

Ethnologie française, 1, 1971

"Le musée des Arts et traditions populaires", Museum, 24 (3), 1972

"Rôle du musée d'art et du musée de sciences humaines et sociales", Museum, 25 (1/2), 1973

"Processus du programme et du projet pour la construction d'un musée", Museum, 26 (3/4), 1974

"Nouveaux aspects du musée d'histoire", Museum, $29(2 / 3), 1977$

"De l'insertion d'un museé dans un bâtiment historique”, Museum, 32 (3), 1980

"Définition évolutive de l'écomusée", Museum, 148,1985

Boka La muséologie selon Georges Henri Rivière, redigert av Hélène Weis (Paris, 1989), er pr. idag den beste kilden om GHRs liv og virke. Den innholder bl.a. en fullstendig liste over GHRs publikasjoner. I boka finner man dessuten tekstene til GHRs forelesninger i museologi ved Sorbonne Universitet.

Marc Maure er mag. art $i$ kunsthistorie, konservator ved Norsk Landbruksmuseum, aktiv utstillingsprodusent. Var på 1970-tallet bl.a. student ved GHR's museologikurs ved Paris Sorbonne Universitet.

Adr: Skarvaveien 95, N-1350 Lommedalen.

Fax +47-675607 47 